\title{
Amino acid substitutions of GLY98, LEU245 and GLU543 in COI1 distinctively affect jasmonate-regulated male fertility in Arabidopsis
}

\author{
HUANG Huang, WANG CuiLi, TIAN HaiXia, SUN Yu, XIE DaoXin ${ }^{*} \&$ SONG SuSheng* \\ Tsinghua-Peking Center for Life Sciences, MOE Key Laboratory of Bioinformatics, School of Life Sciences, Tsinghua University, \\ Beijing 100084, China
}

Received October 16, 2013; accepted November 20, 2013

\begin{abstract}
Jasmonate (JA) regulates various plant defense and developmental processes. The F-box protein CORONATINE INSENSITIVE 1 (COI1) perceives JA signals to mediate diverse plant responses including male fertility, root growth, anthocyanin accumulation, and defense against abiotic and biotic stresses. In this study, we carried out genetic, physiological and biochemical analysis on a series of coil mutant alleles, and found that different amino acid mutations in COI1 distinctively affect JA-regulated male fertility in Arabidopsis. All the JA responses are disrupted by the COI1 mutations W467* in coil-1, Q343* (coil-6), G369E (coil-4), G98D (coi1-5), G155E (coil-7), D452A (coil-9) and L490A (coil-10), though the coil-5 mutant $\left(\mathrm{COI} 1^{\mathrm{G} 98 \mathrm{D}}\right)$ contains adequate COI1 protein ( $60 \%$ of wild-type). Interestingly, the low basal level of COI1 ${ }^{\mathrm{E} 543 \mathrm{~K}}$ in the coil-8 mutant ( $10 \%$ of wild-type COI1 level) is sufficient for maintaining male fertility ( $\sim 50 \%$ of wild-type fertility); the coil-2 mutant with low level of COI $1^{\mathrm{L} 245 \mathrm{~F}}$ ( $\sim 10 \%$ of wild-type) is male sterile under normal growth condition $\left(22^{\circ} \mathrm{C}\right)$ but male fertile ( $\sim 80 \%$ of wild-type fertility) at low temperature $\left(16^{\circ} \mathrm{C}\right)$; however, both coil-2 and coil-8 are defective in the other JA responses (root growth, anthocyanin accumulation, and plant response to the pathogen Pst DC3000 infection).
\end{abstract}

COI1, coil-2, coi1-5, coil-8, jasmonate, male fertility

Citation: Huang H, Wang CL, Tian HX, Sun Y, Xie DX, Song SS. Amino acid substitutions of GLY98, LEU245 and GLU543 in COI1 distinctively affect jasmonate-regulated male fertility in Arabidopsis. Sci China Life Sci, 2014, 57: 145-154, doi: 10.1007/s11427-013-4590-1

Jasmonates (JAs), including jasmonic acid, methyljasmonate (MeJA), jasmonate-isoleucine (JA-Ile) and their oxylipin derivatives [1,2], control various aspects of plant development and growth processes, including plant fertility [3-5], root growth [6,7], trichome formation [8,9] and leaf senescence [10,11], and regulate secondary metabolism [12], such as anthocyanin accumulation [8], glucosinolate biosynthesis [13] and sesquiterpene accumulation [14]. In addition, JAs function as defense signals to mediate plant defense responses against abiotic and biotic stresses, such as ozone exposure [15], drought [16], wounding [17], herbi-

*Corresponding author (email:songss@tsinghua.edu.cn; daoxinlab@tsinghua.edu.cn) vore attack [18-20] and necrotrophic pathogen infection [21-25].

The F-box protein CORONATINE INSENSITIVE1 (COI1) [26] forms the $\mathrm{SCF}^{\mathrm{COII}}$ complex with ASK1/ASK2, Cullin and Rbx1 [27-29], perceives JA signals [30], and recruits Jasmonate-ZIM-domain (JAZ) proteins [31-33] for ubiquitination and subsequent degradation via the $26 \mathrm{~S}$ proteasome pathway. The N-terminal tri-helical F-box motif in COI1 binds to ASK1 [34], while the COI1 C-terminal horseshoe-shaped solenoid, consisting of the 18 LRRs and the four loops (loop-2, loop-12, loop-14 and loop-C), binds to JA-Ile, the bioactive form of JA [35], generating subsequent surface for further interaction with JAZ proteins [34]. 
JAZ proteins interact with various downstream transcription factors, including transcriptional activators MYB21/MYB24 [3], MYC2/MYC3/MYC4 [36-38], WD-repeat/bHLH/MYB complex [8], EIN3/EIL1 [39], and transcriptional repressors bHLH subgroup IIId factors [40-42] to regulate their respective JA responses. JA-induced degradation of JAZ proteins releases the downstream transcriptional factors, leading to antagonistical and coordinated regulation of various JA responses.

The COI1 perceives JA signals to mediate diverse plant responses including developmental processes, secondary metabolism, and defense against abiotic and biotic stresses. In this study, we found that different JA responses require different levels of functional COI1 protein through genetic, physiological and biochemical analysis on a series of coil mutant alleles which harbored various amino acid mutations including G98D in the coil-5 mutant, G155E (coil-7), L245F(coil-2), Q343* (coil-6), G369E (coil-4), D452A (coil-9), W467* (coil-1), L490A (coil-10) and E543K (coil-8). We showed that the amino acid mutations in the COII gene have distinct effect on COI1 function in regulating male fertility: (i) the low basal level of $\mathrm{COI} 1^{\mathrm{E} 543 \mathrm{~K}}$ protein ( $10 \%$ of wild-type) is adequate for maintaining male fertility in the coil-8 mutant ( $\sim 50 \%$ of wild-type fertility), but not for other JA responses including JA-regulated root growth, anthocyanin accumulation, and plant response to the pathogen Pst DC3000 inoculation; (ii) the amino acid substitution L245F in coil-2 significantly attenuates JA-regulated male fertility under normal temperature, whereas $\mathrm{COI} 1^{\mathrm{L} 245 \mathrm{~F}}$ is able to restore male fertility $(\sim 80 \%$ of wild-type fertility) by low temperature treatment without affecting the COI1 protein level; (iii) all the JA responses including male fertility are completely abolished by $\mathrm{COI} 1^{\mathrm{G} 98 \mathrm{D}}$ mutation though adequate $\mathrm{COI} 1^{\mathrm{G} 98 \mathrm{D}}$ protein is retained in coil-5 ( $60 \%$ of wild-type COI1 level), and the other remaining amino acid changes G155E (coil-7), Q343* (coil-6), G369E (coil-4), D452A (coil-9), W467* (coil-1), and L490A (coil-10) completely abolish the COI1 stability and disrupt all the JA responses including male fertility.

\section{Materials and methods}

\subsection{Materials and growth conditions}

The Arabidopsis thaliana Col-0 wild-type, coil-1, coil-2, coil-4, coil-5, coil-6, coil-7, coil-8, coil-9 and coil-10 were described previously [28,30]. The coil-1 and coil-2 mutants were identified by CAPS markers using the primer pairs 5'-GGTTCTCTTTAGTCTTTAC-3' and 5'-GCCAGAGAGTAGTAAGCCAA-3', and 5'-CTTGAGGTTTTAAACTTCTAC-3' and 5'-CTCGAGAACTTCCAAATTAGGAC-3', and restriction endonucleases $X \mathrm{~cm}$ I and Hyp188 III, respectively. The genotypes of coil-4, coil-5, coil-6, coil-7, coil-8, coil-9 and coil-10 were verified by sequencing. The Arabidopsis thaliana seeds were plated on Murashige and Skoog (MS) medium (Sigma, St. Louis, MO, USA) with $3 \%$ sucrose, chilled at $4{ }^{\circ} \mathrm{C}$ for $3 \mathrm{~d}$, and transferred to a growth condition under a light/dark photoperiod of $16 \mathrm{~h} / 8 \mathrm{~h}$ at $16^{\circ} \mathrm{C}$ or $22^{\circ} \mathrm{C}$.

For observation of male fertility from the primary inflorescences, Col-0, coil-1, coil-2, coil-4, coil-5, coil-6, coil-7, coil-8, coil-9 and coil-10 were grown under a light/dark photoperiod of $16 \mathrm{~h} / 8 \mathrm{~h}$ at $22^{\circ} \mathrm{C}$ (for normal temperature) for $45 \mathrm{~d}$, or grown under a light/dark photoperiod of $16 \mathrm{~h} / 8 \mathrm{~h}$ at $22^{\circ} \mathrm{C}$ for four weeks (for normal bolting), and transferred to a growth condition with a light/dark photoperiod of $16 \mathrm{~h} / 8 \mathrm{~h}$ at $16^{\circ} \mathrm{C}$ (for low temperature treatment) for another $32 \mathrm{~d}$. The flowers and stamens at floral stage 13 [43] from the primary inflorescences were presented.

\subsection{RT-PCR and quantitative real-time PCR}

For RT-PCR or quantitative real-time PCR analysis, the Arabidopsis seedlings were grown under a light/dark photoperiod of $16 \mathrm{~h} / 8 \mathrm{~h}$ at $16^{\circ} \mathrm{C}$ or $22^{\circ} \mathrm{C}$ for two weeks, then harvested for RNA extraction. Reverse transcription was performed using TransScript One-Step gDNA Removal and cDNA Synthesis SuperMix Kit (Transgene Biotech, Beijing, China). For reverse transcription (RT) PCR, amplifications were performed with 25 cycles for both ACTIN1 and COII. Amplified transcripts were detected by ethidium bromide-stained agarose gels. ACTIN1 was used as the normalization control. The primers used for RT-PCR are as follows: Actin1: 5'-TGTTGAGAAGAACTACGAGC-3' and 5'-AAGCACTTCCTGTGAACAAT-3', COI1: 5'-TAGAGGTCCTTGCACAGTACTG-3' and 5'-CATCTCTAGCTTCTGTAGAT-3'.

Quantitative real-time (qRT) PCR was performed using the ABI7500 real-time PCR system and RealMasterMix (SYBR Green I) (TAKARA, Japan). ACTIN8 was used as the internal control. All the experiments were repeated three times. The primers used for qRT-PCR analysis are as follows: Actin8: 5'-TCAGCACTTTCCAGCAGATG-3' and 5'-CTGTGGACAATGCCTGGAC-3', COI1: 5'-GTGTCCTAATTTGGAAGTTCTCG-3' and 5'-CTCCATTCCTTGTTCATCTGC-3'.

\subsection{Immunoblot analysis}

For immunoblot analysis of COI1 protein, the Arabidopsis seedlings were grown under a light/dark photoperiod of $16 \mathrm{~h} / 8 \mathrm{~h}$ at $16^{\circ} \mathrm{C}$ or $22^{\circ} \mathrm{C}$ for two weeks. The total protein was extracted from leaves of each genotype using extraction buffer (50 mmol L ${ }^{-1}$ Tris-Cl, pH 7.8, $100 \mathrm{mmol} \mathrm{L}^{-1} \mathrm{NaCl}$, $10 \%$ (v/v) glycerol, and $20 \mathrm{mmol} \mathrm{L}^{-1} \beta$-mercaptoethanol), measured by Broadford method, separated by $10 \%$ SDS-PAGE gel, and transferred to PVDF membrane. Membrane was blocked by $5 \%$ milk power in PBST solution (PBST: $8 \mathrm{~g} \mathrm{~L}^{-1} \mathrm{NaCl}, 0.2 \mathrm{~g} \mathrm{~L}^{-1} \mathrm{KCl}, 1.44 \mathrm{~g} \mathrm{~L}^{-1}$ 
$\mathrm{Na}_{2} \mathrm{HPO}_{4}, 0.24 \mathrm{~g} \mathrm{~L}^{-1} \mathrm{KH}_{2} \mathrm{PO}_{4}, 0.1 \%$ Tween 20) at room temperature for $2 \mathrm{~h}$, incubated with the primary antibody (1:500 dilution) overnight at $4^{\circ} \mathrm{C}$ and secondary antibody ( $1: 1000$ dilution) at room temperature for $2 \mathrm{~h}$. The protein bands were detected by chemiluminescence detection reagents (Applygen Technologies Inc., Beijing, China). The relative abundance of COI1 was calculated by the software from FluorChem M MultiFluor System (Alpha).

\subsection{Measurement of root length and anthocyanin con- tent}

For measurement of root length and anthocyanin content, seeds were grown on MS medium with $0,1,5,10$ or 25 $\mu \mathrm{mol} \mathrm{L}{ }^{-1} \mathrm{MeJA}$, chilled at $4{ }^{\circ} \mathrm{C}$ for $3 \mathrm{~d}$, and transferred to a growth condition with a light/dark photoperiod of $16 \mathrm{~h} / 8 \mathrm{~h}$ at $16^{\circ} \mathrm{C}$ or $22^{\circ} \mathrm{C}$. The 11 -day-old seedlings for each genotype were used for measurement of root length or anthocyanin content with methods as described previously [40]. The relative root length was presented as a percentage of root length on MS medium. The anthocyanin content was presented as $\left(A_{535}-A_{650}\right) / g$ fresh weight. The experiments were repeated three times.

\subsection{Infection with bacterial pathogen}

The Pseudomonas syringae pv tomato (Pst) DC3000 bacteria were cultured overnight, harvested at $2000 \times g$ for $3 \mathrm{~min}$, washed three times using $10 \mathrm{mmol} \mathrm{L} \mathrm{LgCl}_{2}$, and finally suspended in $10 \mathrm{mmol} \mathrm{L}^{-1} \mathrm{MgCl}_{2}$. Twenty-four 4-week- old plants were sprayed with $1 \times 10^{8}$ (colony-forming units) $/ \mathrm{mL}$ bacteria with $0.02 \%$ Silwet L-77. The infection symptoms were observed at three days after infection. The number of bacterial population was measured as previously described [44]. The experiment was repeated three times.

\section{Results}

\subsection{Mutations in COI1 attenuate JA-regulated plant responses}

Previous genetic screening identified a series of coil mutant alleles from ethyl methanesulfonate-mutagenized Arabidopsis seeds [28,30]. The coil-2, coil-4, coil-7, coil-8, coil-9, coil-10 and coil-5 mutant alleles respectively harbored an amino acid substitution L245F, G369E, G155E, E543K, D452A, L490A and G98D (Figure 1A and B), while the amino acid $\mathrm{W} 467$ and Q343 of COI1 were respectively replaced by an early stop codon in the coil-1 and coil-6 mutants (Figure 1A and B). The amino acid changes are presented in the different positions of the LRRs or loops in the structural ribbon diagram of COI1 (Figure 1B). The Xcm I- and Hypl88 III-based CAPS markers were developed to efficiently identify the coil-1 and coil-2 allele respectively (Figure 1C) [26].
To examine the effect of mutations in COI1 on JA-inhibitory root growth, we compared root growth among these coil mutants and wild-type seedlings grown on $\mathrm{Mu}-$ rashige and Skoog (MS) medium supplied with different concentrations of MeJA for $11 \mathrm{~d}$. As shown in Figure 2A and $\mathrm{B}$, root length of all the coil mutant seedlings was not obviously inhibited by MeJA (data not shown), though the root length of coil-2 and coil-8 was slightly attenuated. MeJA exhibited obvious inhibition on the root growth of wild-type seedlings, as expected. These results demonstrate that all the amino acid changes of W467*, Q343*, L245F, G369E, G155E, E543K, D452A, L490A and G98D in COI1 significantly attenuate the JA-inhibitory root growth.

To test the effect of mutations in COI1 on JA-induced anthocyanin accumulation, we measured the anthocyanin content in the 11-day-old seedlings of wild-type and coil mutants grown on MS medium with different concentrations of MeJA. Consistent with previous observations [40], the wild-type seedlings significantly accumulated anthocya$\operatorname{nin}(\sim 3,8,14$ or 20 -fold) when treated with MeJA $(1,5,10$ or $25 \mu \mathrm{mol} \mathrm{L}{ }^{-1}$ ) (Figure $2 \mathrm{C}$ and $\mathrm{D}$ ). However, MeJA treatment was unable to significantly induce anthocyanin accumulation in all the coil mutant seedlings though coil-2 and coil-8 displayed a weak increase of anthocyanin accumulation in response to JA treatment (Figure $2 \mathrm{C}$ and D, data not shown). These data suggest that the amino acid changes of W467*, Q343*, L245F, G369E, G155E, E543K, D452A, L490A and G98D in COI1 severely attenuate the JA-induced anthocyanin accumulation.

A previous study showed that the coil-16 mutant [45], in addition to the L245F mutation in COI1, harbored the pen2-4 mutation in the PENETRATION2 (PEN2) gene that is closely linked to the COII gene, which may alter the non-host resistance of the coil mutant [46]. We found that the coil-2 mutant (L245F), coil-5 (G98D) and coil-8 (E543K) did not harbor pen2-4 mutation using the pen2-4 mutation-specific CAPS marker (data not shown). We further inoculated the bacterial strain Pseudomonas syringae pv tomato (Pst) DC3000 onto four-week-old plants of coil mutants and wild type. We found that three days after spray with Pst DC3000, significant bacterial propagation and strong disease syndrome occurred in wild-type plants (Figure $2 \mathrm{E}$ and $\mathrm{F}$ ), which is consistent with previous results [47]. All the coil mutants displayed much reduced bacterial propagation and leaf disease syndrome though coil-2 and coil-8 exhibited a little more susceptible symptoms (Figure $2 \mathrm{E}$ and $\mathrm{F}$, data not shown). These experiments show that JA-mediated plant response to the Pst DC3000 inoculation is obviously affected by the amino acid changes of W467*, Q343*, L245F, G369E, G155E, E543K, D452A, L490A and G98D in COI1.

Taken together, these results demonstrate that all the amino acid changes in COI1, including W467*, Q343*, L245F, G369E, G155E, E543K, D452A, L490A and G98D, significantly attenuate the COI1 function in regulating the 
A 1 MEDPDIKRCK LSCVATVDDV IEQVMTYITD PKDRDSASLV CRRWFKIDSE TREHVTMALC

61 YTATPDRLSR RFPNLRSLKL KGKPRAAMFN LIPENWGGYV TPWVTEISNN LRQLKSVHFR $\operatorname{coil}-5$ (D)

121 RMIVSDLDLD RLAKARADDL ETLKLDKCSG FTTDGLLSIV THCRKIKTLL MEESSFSEKD coil-7 $\underset{\text { (E) }}{\boldsymbol{\nabla}}$

181 GKWLHELAQH NTSLEVLNFY MTEFAKISPK DLETIARNCR SLVSVKVGDF EILELVGFFK

241 AAANLEEFCG GSLNEDIGMP EKYMNLVFPR KLCRLGLSYM GPNEMPILFP FAAQIRKLDL coil-2 (F)

301 LYALLETEDH CTLIQKCPNL EVLETRNVIG DRGLEVLAQY CKQLKRLRIE RGADEQGMED $\operatorname{coil}-6\left(^{\circ}\right)$

361 EEGLVSQRGL IALAQGCQEL EYMAVYVSDI TNESLESIGT YLKNLCDFRL VLLDREERIT coil-4 (E)

421 DLPLDNGVRS LLIGCKKLRR FAFYLRQGGL TDLGLSYIGQ YSPNVRWMLL GYVGESDEGL

481 MEFSRGCPNL QKLEMRGCCF SERAIAAAVT KLPSLRYLWV QGYRASMTGQ DLMQMARPYW coil-10(A)

541 NIELIPSRRV PEVNQQGEIR EMEHPAHILA YYSLAGQRTD CPTTVRVLKE PI

$\operatorname{coil}-8(\mathrm{~K})$
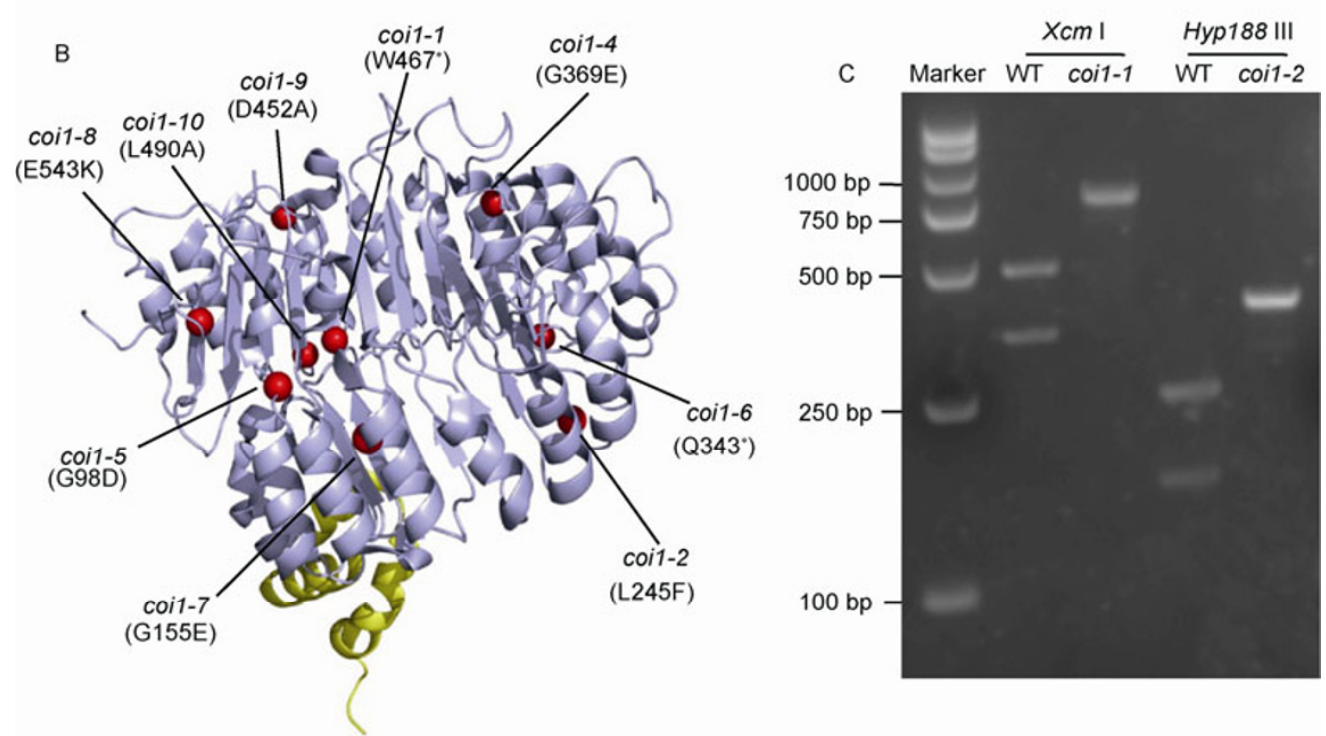

Figure 1 Distribution of the amino acid mutations in COI1. A, Amino acid sequence of COI1. The amino acid mutations are marked by arrows. The asterisks indicate the early translation stop. B, The amino acid mutations G98D in loop-2 in coil-5 mutant, G155E (4th LRR, coil-7), L245F (7th LRR, coil-2), Q343* (11th LRR, coil-6), G369E (12th LRR, coil-4), D452A (15th LRR, coil-9), W467* (15th LRR, coil-1), L490A (16th LRR, coil-10) and E543K (18th LRR, coil-8) are marked by red space fill in the COI1 ribbon diagram that is generated according to previous structural data [34]. The asterisks indicate the early translation stop. C, Verification of coil-1 and coil-2 by CAPS markers. The PCR-amplified 810-bp fragment of COII from WT and coil-1, or 393-bp fragment from WT and coil-2 was digested respectively by restriction endonucleases Xcm I or Hyp 188 III (see Materials and methods for detail).

JA-inhibitory root growth, JA-induced anthocyanin accumulation, and JA-mediated plant response to the pathogen Pst DC3000 inoculation.

\subsection{G98, L245 and E543 in COI1 play distinct roles in JA-regulated plant male fertility}

To investigate whether the mutations in COI1 affect the JA-regulated male fertility, we compared the filament length, anther dehiscence, pollen viability and fertile siliques in the primary inflorescence of the wild-type and coil mutant plants grown at $22^{\circ} \mathrm{C}$. We found that the coil-1, coil-4, coil-5, coil-6, coil-7, coil-9 and coil-10 plants were completely male sterile. All the flowers in these plants exhibited unelongated filaments, indehiscent anthers and unviable pollen grains (Figure 3C, data not shown). These plants were not able to produce siliques with seeds (Figure $3 \mathrm{~A}$ and $\mathrm{B})$.

Interestingly, when grown at $22^{\circ} \mathrm{C}$, the coil-2 mutant plants exhibited severe reduction in male fertility. Most of the flowers from coil-2 produced unelongated filaments, indehiscent anthers and unviable pollen grains (Figure 3C, 

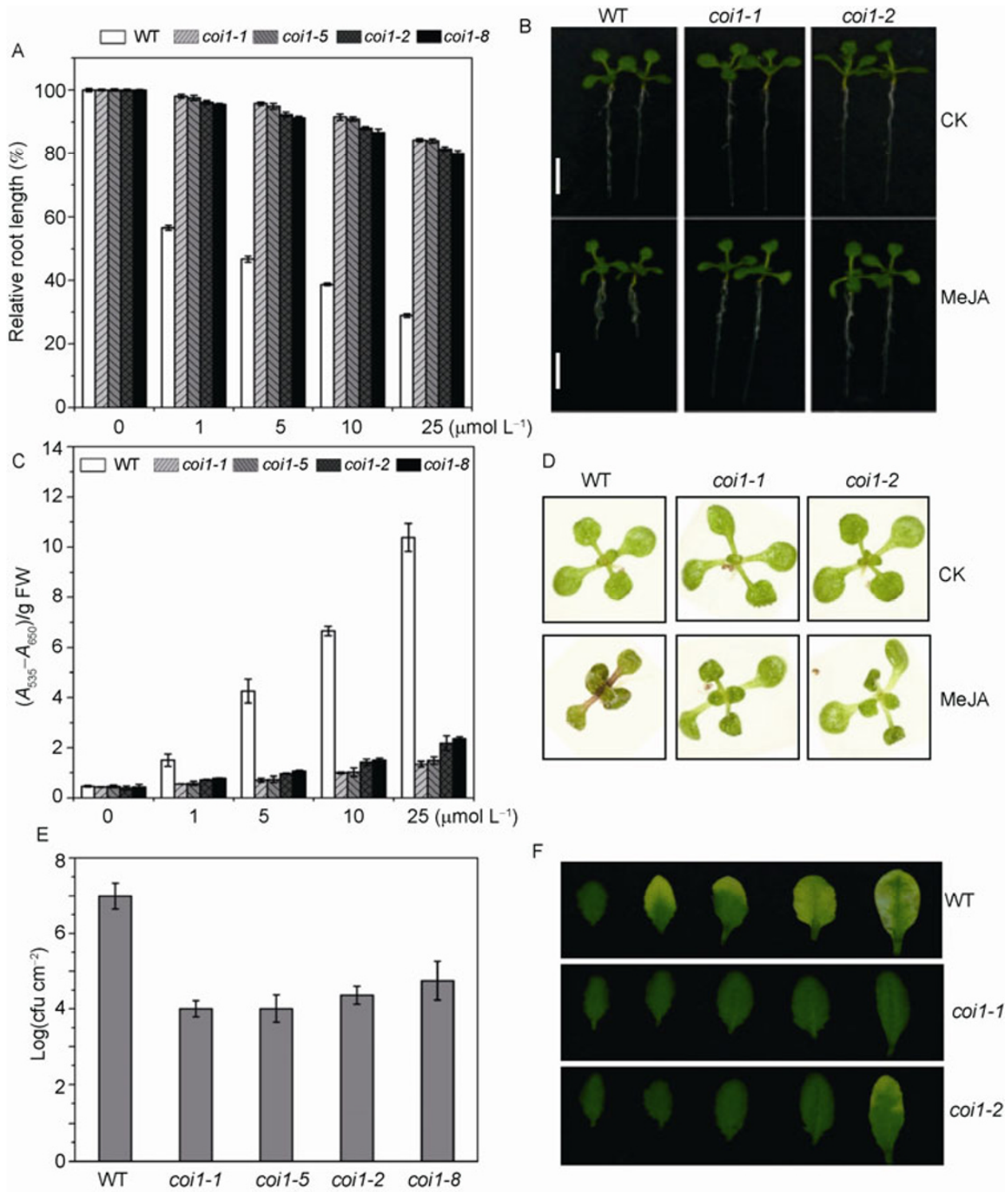

Figure 2 JA-mediated root growth, anthocyanin accumulation and plant response to the pathogen Pst DC3000 inoculation in the coil mutants. A, Relative root length for 11-day-old seedlings of Col-0 (WT), coil-1, coil-5, coil-2 and coil-8 grown on MS medium with $0,1,5,10$ or $25 \mu$ mol L ${ }^{-1} \mathrm{MeJA}_{\text {at }} 22^{\circ} \mathrm{C}$. Relative root length is expressed as a percentage of root length on MS medium. Error bars represent SE $(n=15)$. B, Root phenotypes of 11-day-old seedlings for WT, coil-1 and coil-2 grown on MS medium without (CK) or with $25 \mu \mathrm{mol} \mathrm{L} \mathrm{L}^{-1} \mathrm{MeJA}$ at $22^{\circ} \mathrm{C}$. Scale bar, $5 \mathrm{~mm}$. C, Anthocyanin contents in the 11-day-old seedlings of WT, coil-1, coil-5, coil-2 and coil-8 grown on MS medium containing 0, 1, 5, 10 or $25 \mu$ mol L $\mathrm{L}^{-1} \mathrm{MeJA}$ at $22^{\circ} \mathrm{C}$. FW, fresh weight. Error bars represent SE $(n=3)$. D, Seedling phenotypes of 11-day-old seedlings for WT, coil-1 and coil-2 grown on MS medium without (CK) or with 25 $\mu \mathrm{mol} \mathrm{L}{ }^{-1} \mathrm{MeJA}$ at $22^{\circ} \mathrm{C}$. E, Bacterial population of Pseudomonas syringae pv tomato (Pst) DC3000 in the leaves of WT, coil-1, coil-5, coil-2 and coil-8 at day 3 post-spray inoculation with $1 \times 10^{8}$ colony-forming units $\mathrm{mL}^{-1}\left(\mathrm{cfu} \mathrm{mL} \mathrm{m}^{-1}\right.$ ) of $P s t$ DC3000. Error bars indicate SE ( $n=3$ ). F, Disease symptoms of leaves from WT, coil-1 and coil-2 at day 3 after spray inoculation.

data not shown). Occasionally, few flowers in coil-2 displayed elongated filament and dehiscent anthers with viable pollen grains, and less than $\sim 5 \%$ siliques from the primary inflorescence of coil-2 could set few seeds (Figure 3A and $\mathrm{B}$ ).

The coil-8 mutant plants were partially fertile, in contrast to the coil-1, coil-2, coil-4, coil-5, coil-6, coil-7, coil-9 and coil-10. More than $\sim 50 \%$ of the coil-8 siliques could set seeds (Figure 3A and B). About half of the flowers in coil-8 could produce normally elongated filament and dehiscent anthers with viable pollen grains (Figure 3C).

We further verified the COI1 level in these coil mutant plants grown at $22^{\circ} \mathrm{C}$. Immunoblot analysis with anti-COI1 antiserum revealed that coil-1, coil-4, coil-6, coil-7, coil-9 and coil-10 contained no COI1 protein at all (Figure $3 \mathrm{D}$, data not shown), while the coil-5 with $\mathrm{COI}^{\mathrm{G} 98 \mathrm{D}}$ substitution contained $\sim 60 \%$ of wild-type COI1 level (Figure $3 \mathrm{D})$. Both coil-2 $\left(\mathrm{COI}{ }^{\mathrm{L} 245 \mathrm{~F}}\right)$ and coil-8 $\left(\mathrm{COI1}^{\mathrm{E} 543 \mathrm{~K}}\right)$ re- 

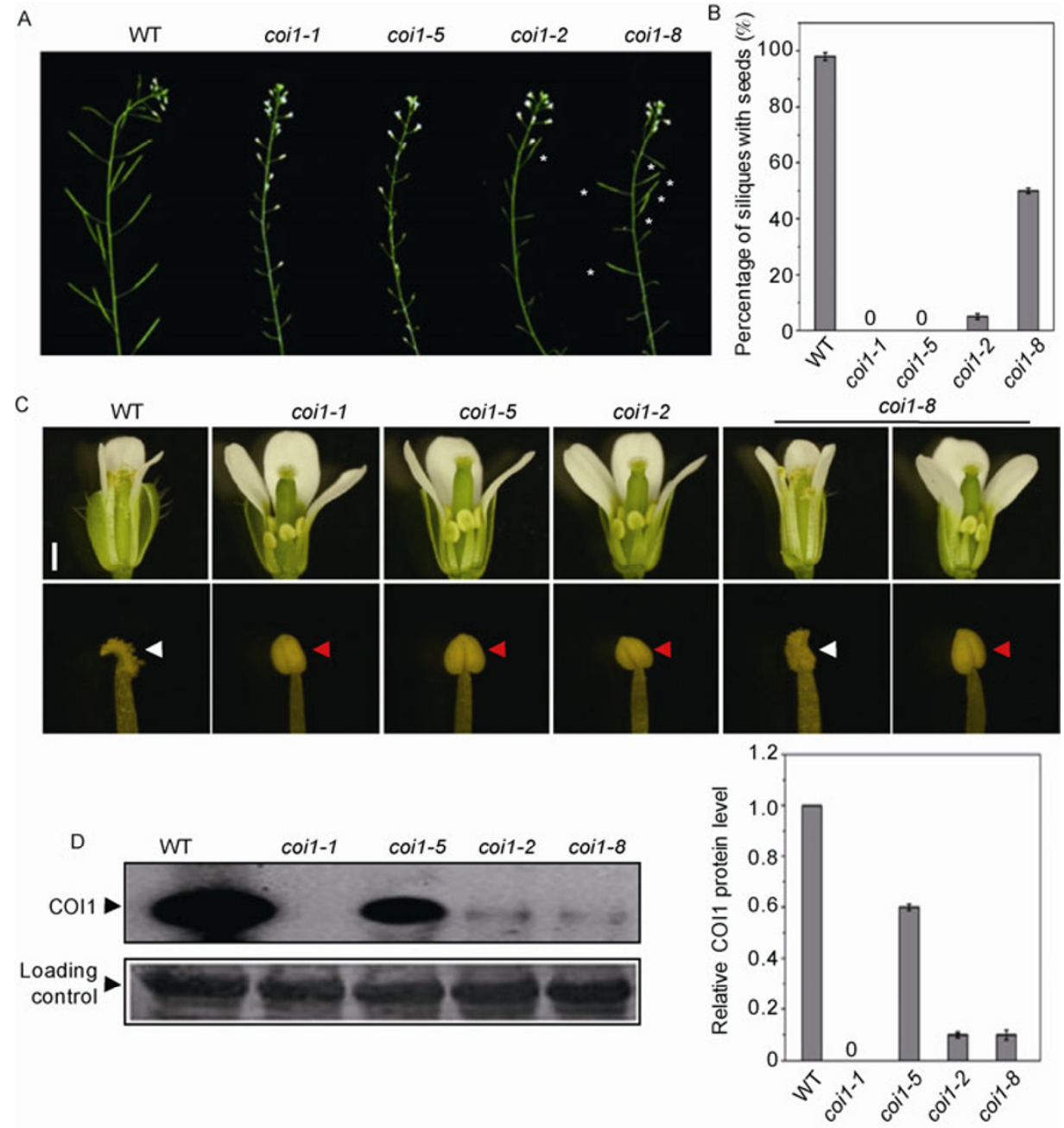

Figure 3 The phenotypic observation of male fertility in the coil mutants. A, Primary inflorescences of WT, coil $1-1$, coil -5 , coil -2 and coil -8 at $22^{\circ} \mathrm{C}$. White asterisks indicate fertile siliques of coil-2 and coil-8. B, Percentage of siliques with seeds in the primary inflorescences of WT, coil-1, coil-5, coil-2 and coil -8 at $22^{\circ} \mathrm{C}$. Error bars represent SE $(n=15)$. C, Flowers (top panel) and anthers (bottom panel) at floral stage 13 from WT, coil-1, coil-5, coil-2 and coil -8 at $22^{\circ} \mathrm{C}$. Scale bar (top panel), $0.5 \mathrm{~mm}$. White arrowheads represent dehiscent anthers, and red arrowheads indicate indehiscent anthers. D, Immunoblot (left panel) and quantitative analysis of COI1 protein level (right panel) in coil mutants at $22^{\circ} \mathrm{C}$. Total proteins were extracted from leaves, separated by $10 \%$ SDS-PAGE, and immunoblotted with COI1 antiserum. The PVDF membrane was stained by Memstain to serve as loading control. The abundance of COI1 in wild type was set to 1.0 for calculating the relative abundance of COI1 protein in other coil mutants.

tained very low level of COI1 protein $(\sim 10 \%$ of the wild-type COI1 level) (Figure 3D).

In summary, our results demonstrate that mutations in the COII gene have distinct effect on COI1 function in regulating male fertility: (i) the amino acid changes $\mathrm{W} 467^{*}$, G369E, G98D, Q343*, G155E, D452A and L490A completely disrupt the COI1 function in regulating male fertility. These mutant plants coil-1, coil-4, coil-5, coil-6, coil-7, coil-9 and coil-10 are male sterile though coil-5 contains adequate $\mathrm{COI} 1^{\mathrm{G} 98 \mathrm{D}}$ ( $\sim 60 \%$ of wild-type); (ii) the amino acid substitution L245F significantly attenuates the JA-regulated male fertility in coil-2; (iii) the E543K substitution has less influence on plant fertility, and the coil-8 plants still maintain $\sim 50 \%$ of wild-type fertility though only $\sim 10 \%$ of $\mathrm{COI} 1^{\mathrm{E} 543 \mathrm{~K}}$ protein is retained.

\subsection{Low temperature treatment restores male fertility in coil-2 (COI1 $\left.{ }^{\mathrm{L} 245 \mathrm{~F}}\right)$}

We next investigated whether treatment of low temperature affected JA-regulated root growth and anthocyanin accumulation in coil-1, coil-2, coil-4, coil-5, coil-6, coil-7, coil-8, coil-9 and coil-10 mutant plants. We found that similar to the seedlings grown at $22^{\circ} \mathrm{C}$, these mutants were still insensitive to JA-regulated root growth and anthocyanin accumulation when grown at $16^{\circ} \mathrm{C}$ (Figure $4 \mathrm{~A}$ and $\mathrm{B}$, data not shown).

We next tested whether treatment of low temperature was able to enhance male fertility in coil-1, coil-2, coil-4, coil-5, coil-6, coil-7, coil-8, coil-9 and coil-10 mutant plants (see Materials and methods). We found that the coil-1, coil-4, coil-5, coil-6, coil-7, coil-9 and coil-10 

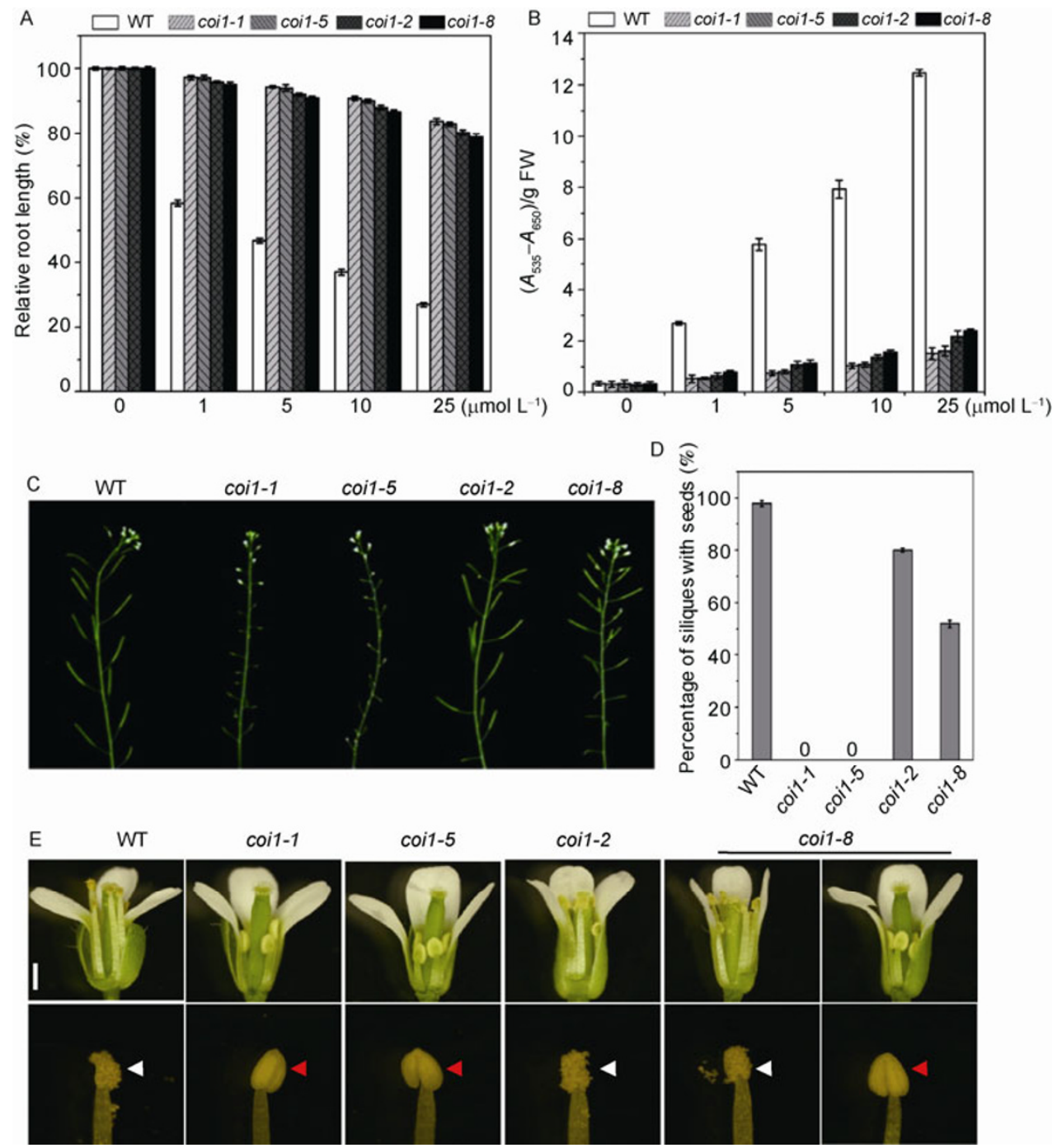

Figure 4 The low temperature treatment restores male fertility in coil-2. A, Relative root length of the 11-day-old seedlings grown on MS medium with the indicated concentrations of MeJA at $16^{\circ} \mathrm{C}$. Error bars represent SE $(n=15)$. B, Anthocyanin contents in the 11-day-old seedlings grown on MS medium containing different concentrations of MeJA at $16^{\circ} \mathrm{C}$. FW, fresh weight. Error bars represent SE $(n=3)$. C, Phenotypes of the primary inflorescences of WT, coil-1, coil-5, coil-2 and coil-8 at $16^{\circ} \mathrm{C}$. D, Percentage of siliques with seeds in the primary inflorescences of WT, coil-1, coil-5, coil-2 and coil-8 at $16^{\circ} \mathrm{C}$. Error bars represent SE $(n=15)$. E, Phenotypes of flowers (top panel) and anthers (bottom panel) at floral stage 13 from WT, coil-1, coil-5, coil-2 and coil -8 at $16^{\circ} \mathrm{C}$. Scale bar (top panel), $0.5 \mathrm{~mm}$. White arrowheads represent dehiscent anthers, and red arrowheads indicate indehiscent anthers.

were completely male sterile under treatment of low temperature $\left(16^{\circ} \mathrm{C}\right)$ (Figure $4 \mathrm{C}$, data not shown), similar to the phenotypes at $22^{\circ} \mathrm{C}$ (Figure 3A). Flowers in these mutant plants were deficient in filament elongation, anther dehiscence and pollen maturation (Figure 4E, data not shown).

Phenotypic observation of plant fertility revealed that treatment of low temperature $\left(16^{\circ} \mathrm{C}\right)$ significantly promoted male fertility in coil-2 but not in coil-8 plants (Figure $4 \mathrm{C}$ and D). $\sim 80 \%$ of siliques in the $16^{\circ} \mathrm{C}$-treated coil-2 plants set seeds whereas only $\sim 5 \%$ of siliques set seeds at $22^{\circ} \mathrm{C}$ (Figures 3A and B, 4C and D). Consistently, most flowers from the $16^{\circ} \mathrm{C}$-treated coil-2 exhibited elongated filaments, dehiscent anthers and viable pollen grains (Figure 4E, data not shown). However, under treatment of low temperature $\left(16^{\circ} \mathrm{C}\right)$, male fertility of the coil $1-8$ plants was not obviously enhanced compared with the $22^{\circ} \mathrm{C}$-treated coil- 8 plants (Figure 3A and B, 4C and D).

Having demonstrated that low temperature recovered the fertility in coil-2, we investigated whether low temperature enhanced the COI1 level in coil-2 and other coil mutants. RT-PCR and qRT-PCR analysis showed that the expression level of COII was similar in the wild type, coil-1, coil-2, coil-4, coil-5, coil-6, coil-7, coil-8, coil-9 and coil-10 at either $16^{\circ} \mathrm{C}$ or $22^{\circ} \mathrm{C}$ (Figure 5A, data not shown). The immunoblot analysis using COI1-antiserum displayed that COI1 protein level was not obviously increased in the $16^{\circ} \mathrm{C}$-treated coil-2, coil-8 and coil-5 (Figure 5B). Similar to the data from the $22^{\circ} \mathrm{C}$-treated plants, COI1 protein was not detectable in coil-1, coil-4, coil-6, coil-7, coil-9 and coil-10 (Figure 5B, data not shown). 

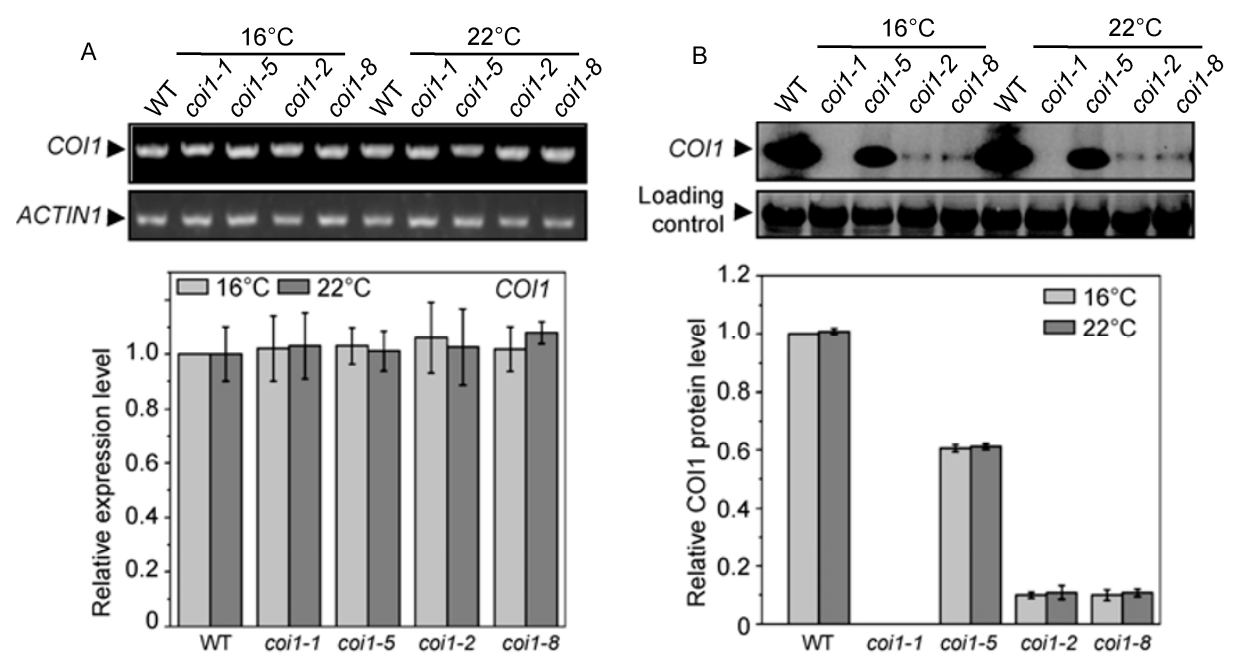

Figure 5 The low temperature treatment cannot influence the COI1 expression. A, RT-PCR (top panel) and quantitative real-time (qRT) PCR (bottom panel) analysis of $\mathrm{COI1}$ transcript level in the indicated seedlings grown at $16^{\circ} \mathrm{C}$ or $22^{\circ} \mathrm{C}$. For RT-PCR analysis, Actin1 was used as the normalization control. For qRT-PCR analysis, Actin 8 was used as the internal control. Error bars represent SE ( $n=3$ ). B, Immunoblot (top panel) and quantitative analysis of COI1 protein level (bottom panel) in WT, coil-1, coil-5, coil-2 and coil- 8 at $16^{\circ} \mathrm{C}$ or $22^{\circ} \mathrm{C}$. The PVDF membrane was stained by Memstain to serve as loading control. Error bars represent SE $(n=3)$. The abundance of COI1 in wild type at $16^{\circ} \mathrm{C}$ was set to 1.0 for calculating the relative abundance of COI 1 protein in the $22^{\circ} \mathrm{C}$-treated WT and all the indicated coil mutants treated with $16^{\circ} \mathrm{C}$ or $22^{\circ} \mathrm{C}$.

In summary, we show that JA-regulated root growth and anthocyanin accumulation of all these tested coil mutants are not obviously affected by low temperature, and the treatment of low temperature has no obvious influence on the COI1 protein level in these coil mutants. However, low temperature treatment is able to obviously restore male fertility in coil-2 (COI1 $\left.{ }^{\mathrm{L} 245 \mathrm{~F}}\right)$, but unable to enhance male fertility in coil-8.

\section{Discussion}

The structure of the ASK1-COI1-(JA-Ile)-JAZ1 degron complex revealed that the COI1 C-terminus consists of 18 LRRs and four loops (loop-2, loop-12, loop-14 and loop-C) forming a binding surface for the bioactive JA-Ile [34]. Here, we carried out biochemical analysis on a series of coil mutant alleles which harbored various amino acid mutations distributed in the COI1 C-terminal LRRs and loops (Figure 1B). We found that the different amino acid mutations exhibited different effect on COI1 stability: the COI $1^{\mathrm{G} 98 \mathrm{D}}$ in the coil-5 mutant was retained at $\sim 60 \%$ of wild-type COI1 level (Figure 3D); the COI1 $1^{\mathrm{L} 245 \mathrm{~F}}$ in coil-2 and $\mathrm{COI} 1^{\mathrm{E} 543 \mathrm{~K}}$ in coil-8 were maintained at $\sim 10 \%$ of wild-type COI1 level (Figure 3D); the remaining COI1 mutations, including $\mathrm{COI}^{\mathrm{W} 467^{*}}$ (coil-1), $\mathrm{COI}^{\mathrm{G} 369 \mathrm{E}}$ (coil-4), $\mathrm{COI}^{\mathrm{Q} 343^{*}}$ (coil-6), COI1 ${ }^{\mathrm{G} 155 \mathrm{E}}$ (coil-7), COI1 ${ }^{\mathrm{D} 452 \mathrm{~A}}$ (coil-9) and $\mathrm{COI} 1^{\mathrm{L} 490 \mathrm{~A}}$ (coil-10), completely abolished COI1 stability (Figure 3D, data not shown).

Further analysis on correlation of the $\mathrm{COI} 1^{\mathrm{L} 245 \mathrm{~F}}$ (coil-2), $\mathrm{COI}^{\mathrm{E} 543 \mathrm{~K}}\left(\right.$ coil-8) and COI1 ${ }^{\mathrm{G} 98 \mathrm{D}}$ (coil-5) protein level with male fertility phenotype revealed that $\mathrm{COI} 1^{\mathrm{L} 245 \mathrm{~F}}, \mathrm{COI} 1^{\mathrm{E} 543 \mathrm{~K}}$ and $\mathrm{COI} 1^{\mathrm{G} 98 \mathrm{D}}$ protein exerted distinct effect on male fertility: coil-5 $\left(\mathrm{COI}^{\mathrm{G} 98 \mathrm{D}}\right)$ was completely male sterile and the $\mathrm{COI}^{\mathrm{G} 98 \mathrm{D}}$ was not functional in JA signaling though $\sim 60 \%$ of $\mathrm{COI} 1^{\mathrm{G} 98 \mathrm{D}}$ protein was retained (Figure 3 ); male fertility in the coil-8 $\left(\mathrm{COI} 1^{\mathrm{E} 543 \mathrm{~K}}\right)$ mutant was relatively less affected ( $\sim 50 \%$ of wild-type fertility), though only $\sim 10 \%$ of protein was detectable (Figure 3 ); the COI1 ${ }^{\mathrm{L} 245 \mathrm{~F}}$ displayed strong effect on both the protein stability (similar protein level with COI $1^{\mathrm{E} 543 \mathrm{~K}}$ ) and male fertility in the $22^{\circ} \mathrm{C}$-grown coil-2 plants (less than $\sim 5 \%$ of wild-type fertility level) (Figure 3 ). It would be interesting to investigate the molecular mechanism in stabilizing these COI1 proteins COI1 ${ }^{\mathrm{L} 245 \mathrm{~F}}$ (coil-2), $\mathrm{COI}^{\mathrm{E} 543 \mathrm{~K}}\left(\right.$ coil-8) and COI1 ${ }^{\mathrm{G} 98 \mathrm{D}}$ (coil-5), and in regulating their function in male fertility.

COI1 was shown to mediate diverse JA responses such as root growth, stamen development, anthocyanin accumulation and response to the bacterial pathogen Pst DC3000 infection. Evidence is limited about whether the various COI1-mediated JA responses require different abundance of the COI1 protein. In this study, we showed that different from other JA responses, JA-regulated male fertility just required low level of COI1 protein: the $\mathrm{COI} 1^{\mathrm{E} 543 \mathrm{~K}}$ and COI $1^{\mathrm{L} 245 \mathrm{~F}}$ protein $(\sim 10 \%$ of wild-type COI1 level) was enough for maintaining male fertility ( $50 \%$ of wild-type fertility) or temperature-sensitive fertility $(\sim 80 \%$ of wild-type fertility), but not for regulating the JA-inhibitory root growth, anthocyanin accumulation and response to the bacterial pathogen Pst DC3000 infection (Figures 2-4). It remains to be elucidated which COI1 dosage is required for regulating other JA responses, such as leaf senescence, trichome formation and defense against insect attack and necrotrophic pathogen infection. We found that all our tested coil mutants including coil-2 (COI1 $\left.{ }^{\mathrm{L} 245 \mathrm{~F}}\right)$ and coil-8 $\left(\mathrm{COI}{ }^{\mathrm{E} 543 \mathrm{~K}}\right.$ ) did not contain the pen2-4 mutation (data not 
shown), which is different from the previously reported coil-16 $\left(\mathrm{COI} 1^{\mathrm{L} 245 \mathrm{~F}}\right)$ mutant with the additional pen $2-4 \mathrm{mu}-$ tation $[45,46]$. As the pen $2-4$ mutation in the PEN2 gene may alter the non-host resistance [46], our coil mutants without the pen 2-4 mutation would be useful for the analysis of JA-regulated plant defense responses.

Low temperature treatment significantly rescued male sterility in coil-2 $\left(\mathrm{COI}^{\mathrm{L} 245 \mathrm{~F}}\right)$, whereas male fertility in coil-8 $\left(\mathrm{COI}^{\mathrm{E} 543 \mathrm{~K}}\right)$ was not affected (Figure 4$)$. Two putative reasons might account for the dramatic recovery of male fertility in coil-2 by low temperature treatment: firstly, low temperature may modulate the function of $\mathrm{COI} 1^{\mathrm{L} 245 \mathrm{~F}}$ (e.g., configuration change of $\mathrm{COI} 1^{\mathrm{L} 245 \mathrm{~F}}$ ) for JA-regulated stamen development; secondly, low temperature may affect the property of the signaling components (e.g., MYB21/ MYB24) [48,49] downstream of COI1 for stamen development. However, the low temperature did not enhance male fertility in coil-8 $\left(\mathrm{COI} 1^{\mathrm{E} 543 \mathrm{~K}}\right)$ that regulates the same downstream signaling components of coil-2 $\left(\mathrm{COI}^{\mathrm{L} 245 \mathrm{~F}}\right)$, which may exclude the second putative reason. It would be interesting to investigate whether and how low temperature modulates the configuration of $\mathrm{COI} 1^{\mathrm{L} 245 \mathrm{~F}}$, generating the functional form of $\mathrm{COI}^{\mathrm{L} 245 \mathrm{~F}}$ for regulation of male fertility.

This work was supported by the National Natural Science Foundation of China (31230008 and 91017012) and Ministry of Agriculture of China (2013ZX08011-006).

1 Browse J. Jasmonate passes muster: a receptor and targets for the defense hormone. Annu Rev Plant Biol, 2009, 60: 183-205

2 Wasternack C, Hause B. Jasmonates: biosynthesis, perception, signal transduction and action in plant stress response, growth and development. An update to the 2007 review in annals of botany. Ann Bot, 2013, 111: 1021-1058

3 Song S, Qi T, Huang H, Ren Q, Wu D, Chang C, Peng W, Liu Y, Peng J, Xie D. The Jasmonate-ZIM domain proteins interact with the R2R3-MYB transcription factors MYB21 and MYB24 to affect jasmonate-regulated stamen development in Arabidopsis. Plant Cell, 2011, 23: 1000-1013

4 McConn M, Browse J. The critical requirement for linolenic acid is pollen development, not photosynthesis, in an Arabidopsis mutant. Plant Cell, 1996, 8: 403-416

5 Song S, Qi T, Huang H, Xie D. Regulation of stamen development by coordinated actions of jasmonate, auxin and gibberellin in Arabidopsis. Mol Plant, 2013, 6: 1065-1073

6 Staswick PE, Su WP, Howell SH. Methyl jasmonate inhibition of root-growth and induction of a leaf protein are decreased in an Arabidopsis thaliana mutant. Proc Natl Acad Sci USA, 1992, 89: 6837-6840

7 Feys BJF, Benedetti CE, Penfold CN, Turner JG. Arabidopsis mutants selected for resistance to the phytotoxin coronatine are male-sterile, insensitive to methyl jasmonate, and resistant to a bacterial pathogen. Plant Cell, 1994, 6: 751-759

8 Qi T, Song S, Ren Q, Wu D, Huang H, Chen Y, Fan M, Peng W, Ren $\mathrm{C}$, Xie D. The Jasmonate-ZIM-domain proteins interact with the WD-repeat/bHLH/MYB complexes to regulate jasmonate-mediated anthocyanin accumulation and trichome initiation in Arabidopsis thaliana. Plant Cell, 2011, 23: 1795-1814

9 Yoshida Y, Sano R, Wada T, Takabayashi J, Okada K. Jasmonic acid control of GLABRA3 links inducible defense and trichome pattern- ing in Arabidopsis. Development, 2009, 136: 1039-1048

10 Ueda J, Kato J. Isolation and identification of a senescence-promoting substance from wormwood (Artemisia absinthium L.). Plant Physiol, 1980, 66: 246-249

11 Shan X, Wang J, Chua L, Jiang D, Peng W, Xie D. A role of Arabidopsis rubisco activase in jasmonate-induced leaf senescence. Plant Physiol, 2011, 155: 751-764

12 De Geyter N, Gholami A, Goormachtig S, Goossens A. Transcriptional machineries in jasmonate-elicited plant secondary metabolism. Trends Plant Sci, 2012, 17: 349-359

13 Schweizer F, Fernandez-Calvo P, Zander M, Diez-Diaz M, Fonseca S, Glauser G, Lewsey MG, Ecker JR, Solano R, Reymond P. Arabidopsis basic helix-loop-helix transcription factors MYC2, MYC3, and MYC4 regulate glucosinolate biosynthesis, insect performance, and feeding behavior. Plant Cell, 2013, 25: 3117-3132

14 Hong GJ, Xue XY, Mao YB, Wang LJ, Chen XY. Arabidopsis MYC2 interacts with DELLA proteins in regulating sesquiterpene synthase gene expression. Plant Cell, 2012, 24: 2635-2648

15 Rao MV, Lee H, Creelman RA, Mullet JE, Davis KR. Jasmonic acid signaling modulates ozone-induced hypersensitive cell death. Plant Cell, 2000, 12: 1633-1646

16 Seo JS, Joo J, Kim MJ, Kim YK, Nahm BH, Song SI, Cheong JJ, Lee JS, Kim JK, Choi YD. OsbHLH148, a basic helix-loop-helix protein, interacts with OsJAZ proteins in a jasmonate signaling pathway leading to drought tolerance in rice. Plant J, 2011, 65: 907-921

17 Robson F, Okamoto H, Patrick E, Harris SR, Wasternack C, Brearley C, Turner JG. Jasmonate and phytochrome A signaling in Arabidopsis wound and shade responses are integrated through JAZ1 stability. Plant Cell, 2010, 22: 1143-1160

18 Howe GA, Jander G. Plant immunity to insect herbivores. Annu Rev Plant Biol, 2008, 59: 41-66

19 McConn M, Creelman RA, Bell E, Mullet JE, Browse J. Jasmonate is essential for insect defense in Arabidopsis. Proc Natl Acad Sci USA, 1997, 94: 5473-5477

20 Li L, Zhao Y, McCaig BC, Wingerd BA, Wang J, Whalon ME, Pichersky E, Howe GA. The tomato homolog of CORONATINEINSENSITIVE1 is required for the maternal control of seed maturation, jasmonate-signaled defense responses, and glandular trichome development. Plant Cell, 2004, 16: 126-143

21 Lorenzo O, Chico JM, Sanchez-Serrano JJ, Solano R. JASMONATEINSENSITIVE1 encodes a MYC transcription factor essential to discriminate between different jasmonate-regulated defense responses in Arabidopsis. Plant Cell, 2004, 16: 1938-1950

22 Thaler JS, Humphrey PT, Whiteman NK. Evolution of jasmonate and salicylate signal crosstalk. Trends Plant Sci, 2012, 17: 260-270

23 Vijayan P, Shockey J, Levesque CA, Cook RJ, Browse J. A role for jasmonate in pathogen defense of Arabidopsis. Proc Natl Acad Sci USA, 1998, 95: 7209-7214

24 Hu P, Zhou W, Cheng Z, Fan M, Wang L, Xie D. JAV1 controls jasmonate-regulated plant defense. Mol Cell, 2013, 50: 504-515

25 Robert-Seilaniantz A, Grant M, Jones JD. Hormone crosstalk in plant disease and defense: more than just jasmonate-salicylate antagonism. Annu Rev Phytopathol, 2011, 49: 317-343

26 Xie DX, Feys BF, James S, Nieto-Rostro M, Turner JG. COI1: an Arabidopsis gene required for jasmonate-regulated defense and fertility. Science, 1998, 280: 1091-1094

27 Ren CM, Pan JW, Peng W, Genschik P, Hobbie L, Hellmann H, Estelle M, Gao B, Peng JR, Sun CQ, Xie DX. Point mutations in Arabidopsis Cullin1 reveal its essential role in jasmonate response. Plant J, 2005, 42: 514-524

28 Xu LH, Liu FQ, Lechner E, Genschik P, Crosby WL, Ma H, Peng W, Huang DF, Xie DX. The SCF ${ }^{\mathrm{CO} 11}$ ubiquitin-ligase complexes are required for jasmonate response in Arabidopsis. Plant Cell, 2002, 14: 1919-1935

29 Yan J, Li H, Li S, Yao R, Deng H, Xie Q, Xie D. The Arabidopsis F-box protein CORONATINE INSENSITIVE1 is stabilized by $\mathrm{SCF}^{\mathrm{CO} I 1}$ and degraded via the $26 \mathrm{~s}$ proteasome pathway. Plant Cell, 2013, 25: 486-498 
30 Yan J, Zhang C, Gu M, Bai Z, Zhang W, Qi T, Cheng Z, Peng W, Luo H, Nan F, Wang Z, Xie D. The Arabidopsis CORONATINE INSENSITIVE1 protein is a jasmonate receptor. Plant Cell, 2009, 21: 2220-2236

31 Chini A, Fonseca S, Fernandez G, Adie B, Chico JM, Lorenzo O, Garcia-Casado G, Lopez-Vidriero I, Lozano FM, Ponce MR, Micol JL, Solano R. The JAZ family of repressors is the missing link in jasmonate signalling. Nature, 2007, 448: 666-671

32 Thines B, Katsir L, Melotto M, Niu Y, Mandaokar A, Liu G, Nomura $\mathrm{K}$, He SY, Howe GA, Browse J. JAZ repressor proteins are targets of the $\mathrm{SCF}^{\mathrm{COI1}}$ complex during jasmonate signalling. Nature, 2007, 448: 661-665

33 Yan YX, Stolz S, Chetelat A, Reymond P, Pagni M, Dubugnon L, Farmer EE. A downstream mediator in the growth repression limb of the jasmonate pathway. Plant Cell, 2007, 19: 2470-2483

34 Sheard LB, Tan X, Mao H, Withers J, Ben-Nissan G, Hinds TR, Kobayashi Y, Hsu FF, Sharon M, Browse J, He SY, Rizo J, Howe GA, Zheng N. Jasmonate perception by inositol-phosphate-potentiated COI1-JAZ co-receptor. Nature, 2010, 468: 400-405

35 Fonseca S, Chini A, Hamberg M, Adie B, Porzel A, Kramell R, Miersch O, Wasternack C, Solano R. (+)-7-iso-jasmonoyl-1isoleucine is the endogenous bioactive jasmonate. Nat Chem Biol, 2009, 5: 344-350

36 Niu Y, Figueroa P, Browse J. Characterization of JAZ-interacting bHLH transcription factors that regulate jasmonate responses in Arabidopsis. J Exp Bot, 2011, 62: 2143-2154

37 Fernandez-Calvo P, Chini A, Fernandez-Barbero G, Chico JM, Gimenez-Ibanez S, Geerinck J, Eeckhout D, Schweizer F, Godoy M, Franco-Zorrilla JM, Pauwels L, Witters E, Puga MI, Paz-Ares J, Goossens A, Reymond P, De Jaeger G, Solano R. The Arabidopsis bHLH transcription factors MYC3 and MYC4 are targets of JAZ repressors and act additively with MYC2 in the activation of jasmonate responses. Plant Cell, 2011, 23: 701-715

38 Cheng Z, Sun L, Qi T, Zhang B, Peng W, Liu Y, Xie D. The bHLH transcription factor MYC3 interacts with the Jasmonate ZIM-domain proteins to mediate jasmonate response in Arabidopsis. Mol Plant, 2011, 4: 279-288

39 Zhu Z, An F, Feng Y, Li P, Xue L, Mu A, Jiang Z, Kim JM, To TK, Li W, Zhang X, Yu Q, Dong Z, Chen WQ, Seki M, Zhou JM, Guo H. Derepression of ethylene-stabilized transcription factors (EIN3/EIL1) mediates jasmonate and ethylene signaling synergy in Arabidopsis. Proc Natl Acad Sci USA, 2011, 108: 12539-12544

40 Song S, Qi T, Fan M, Zhang X, Gao H, Huang H, Wu D, Guo H, Xie D. The bHLH subgroup IIId factors negatively regulate jasmonatemediated plant defense and development. PLoS Genet, 2013, 9: e1003653

41 Sasaki-Sekimoto Y, Jikumaru Y, Obayashi T, Saito H, Masuda S, Kamiya Y, Ohta H, Shirasu K. Basic helix-loop-helix transcription factors jasmonate-associated MYC2-LIKE1 (JAM1), JAM2, and JAM3 are negative regulators of jasmonate responses in Arabidopsis. Plant Physiol, 2013, 163: 291-304

42 Nakata M, Mitsuda N, Herde M, Koo AJ, Moreno JE, Suzuki K, Howe GA, Ohme-Takagi M. A bHLH-type transcription factor, ABA-INDUCIBLE BHLH-TYPE TRANSCRIPTION FACTOR/ JA-ASSOCIATED MYC2-LIKE1, acts as a repressor to negatively regulate jasmonate signaling in Arabidopsis. Plant Cell, 2013, 25: 1641-1656

43 Smyth DR, Bowman JL, Meyerowitz EM. Early flower development in Arabidopsis. Plant Cell, 1990, 2: 755-767

44 Katagiri F, Thilmony R, He SY. The Arabidopsis thalianapseudomonas syringae interaction. Arabidopsis Book, 2002, 1: e0039

45 Ellis C, Turner JG. A conditionally fertile coil allele indicates cross-talk between plant hormone signalling pathways in Arabidopsis thaliana seeds and young seedlings. Planta, 2002, 215: 549-556

46 Westphal L, Scheel D, Rosahl S. The coil-16 mutant harbors a second site mutation rendering PEN2 nonfunctional. Plant Cell, 2008, 20: 824-826

47 Yang DL, Yao J, Mei CS, Tong XH, Zeng LJ, Li Q, Xiao LT, Sun TP, Li J, Deng XW, Lee CM, Thomashow MF, Yang Y, He Z, He SY. Plant hormone jasmonate prioritizes defense over growth by interfering with gibberellin signaling cascade. Proc Natl Acad Sci USA, 2012, 109: E1192-1200

48 Mandaokar A, Thines B, Shin B, Lange BM, Choi G, Koo YJ, Yoo YJ, Choi YD, Choi G, Browse J. Transcriptional regulators of stamen development in Arabidopsis identified by transcriptional profiling. Plant J, 2006, 46: 984-1008

49 Cheng H, Song S, Xiao L, Soo HM, Cheng Z, Xie D, Peng J. Gibberellin acts through jasmonate to control the expression of $M Y B 21$, $M Y B 24$, and MYB57 to promote stamen filament growth in Arabidopsis. PLoS Genet, 2009, 5: e1000440

Open Access This article is distributed under the terms of the Creative Commons Attribution License which permits any use, distribution, and reproduction in any medium, provided the original author(s) and source are credited. 